\title{
The Kenyan Luo migration study: observations on the initiation of a rise in blood pressure
}

\author{
N R Poulter, K T Khaw, B E C Hopwood, M Mugambi, W S Peart, G Rose, P S Sever
}

St Mary's Hospital, London W2 1NY

N R Poulter, MRCP, honorary consultant physician and epidemiologist

$\mathrm{K} \mathrm{T}$ Khaw, MRCP, Wellcome research fellow

W S Peart, FRS, professor of medicine

P S Sever, FRCP, professor of clinical pharmacology and therapeutics

Wellcome Trust Research Laboratories, Nairobi, Kenya

B E C Hopwood, FFCM, director

Kenya Medical Research Institute, Nairobi, Kenya M Mugambi, MD, director

London School of Hygiene and Tropical Medicine, London WC1

G Rose, DM, professor of

epidemiology

Correspondence to: Dr Poulter, Department of Community Medicine,

University College and Middlesex School of Medicine, London WCIE 6EA.

BrMed f 1990;300:967-72

\section{Abstract}

Objective-To demonstrate the magnitude, timing, and cause of changes in blood pressure that occur in migrants from a low blood pressure population on moving to an urban area.

Design-A controlled longitudinal observational study of migrants as soon after migration as possible and follow up at three, six, 12, 18, and 24 months after migration. A cohort of controls living in a rural area who were matched for age, sex, and locality were also observed at the same periods.

Setting-35 Villages on the northern shores of Lake Victoria in western Kenya and Nairobi.

Participants - 325 Members of the Luo tribe aged 15 to 34 years who had migrated to Nairobi and 267 controls living in villages. The numbers of both groups reduced during follow up such that only 63 migrants and 143 controls were followed up for two years.

Main outcome measures - A medical questionnaire and three 24 hour diet histories were completed by migrants and controls. Height, weight, pulse, and blood pressure were measured. Three 12 hour overnight urine samples were collected from all participants and analysed for sodium, potassium, and creatinine concentrations.

Results-The mean systolic blood pressure of migrants was significantly higher than that of controls throughout the study, and the distribution of blood pressure was shifted to the right compared with controls. The mean diastolic blood pressure of the two groups diverged over time. Blood pressure differences were not due to selective migration. The migrants' mean urinary sodium:potassium ratio was higher than that of controls $(p<0.001)$ throughout, and weight and pulse rate were also higher among migrants, although differences diminished with time.

Conclusions-Urinary sodium:potassium ratio, pulse rate, and weight are important predictors of increased blood pressure among migrants from a low blood pressure community and may also be implicated in the initiation of essential hypertension.

\section{Introduction}

Raised blood pressure is a strong independent risk factor for cardiovascular disease,' the leading cause of morbidity and mortality in modern Western society. Prospective epidemiological data suggest that in Westernised societies most of the population have a blood pressure above the optimum for risk of cardiovascular disease ${ }^{13}$ and that blood pressure rises sharply with age, although these levels and the rise in blood pressure with age are not universal. Several communities have been reported to have a low mean blood pressure, which shows little increase with age, ${ }^{4-6}$ and other cross sectional comparative studies have shown that when people from such communities live in more modern surroundings their blood pressure levels are higher and do rise with age, thereby emphasising the importance of environmental factors in determining blood pressure..$^{7.9}$

The cross sectional data available can only suggest specific factors responsible for changes in blood pressure associated with a changed environment and the time scale over which these changes occur. We hypothesised that the factors inducing changes in blood pressure are likely to be the critical aetiological agents responsible for essential hypertension. ${ }^{\circ 0} \mathrm{We}$ report the results of a longitudinal study of migrants leaving a population with a low mean blood pressure in western Kenya for an urban environment.

\section{Subjects and methods}

Details of the initial cross sectional studies, which established that a rural farming community of the Luo tribe in western Kenya had a low mean blood pressure and that people of the same tribe and community residing in Nairobi had higher blood pressure, have been described elsewhere."

In the present study fieldworkers visited homes in each of the 35 villages in the rural study area. We also received information from one or two health workers in each village at least once a week regarding names and contact addresses of anyone aged over 14 years who had migrated to Nairobi on a potentially permanent basis. This information was posted to Nairobi, where other Luo fieldworkers attempted to locate these migrants as quickly as possible. After migrants had been located their eligibility for the study was established $(\geqslant 15$ years old, stated intent to live in Nairobi, and contacted within 60 days of arriving in Nairobi) and they were visited at home by one of the two study observers.

With the help of translators, the observers administered a questionnaire on age, sex, marital history, parity, menstrual history, history of drugs taken, consumption of alcohol, smoking, occupation, education, housing, and length of time spent living in any urban residence. The subject's height, weight, and pulse rate were measured and two blood pressure recordings were taken (after five minutes' lying; systolic and diastolic phase $\mathrm{V}$ ) with a random zero sphygmomanometer. The ambient temperature and time of day were recorded and a "spot" urine sample was collected. Each subject was asked to provide three 12 hour overnight urine samples. A diet historian collected the samples and elicited from each subject three 24 hour diet histories by a standard semiquantitative recall method. Migrants were revisited at approximately three, six, 12, 18, and 24 months after their arrival in Nairobi, when the same investigations were repeated.

Urine samples were collected in 2 litre plastic bottles 
containing boric acid as a preservative and refrigerated within 12 hours of collection. The volume of each overnight sample was recorded, and urine was analysed for sodium, potassium, and creatinine in the Wellcome Trust Research Laboratories in Nairobi. Total 12 hour, overnight excretion of sodium, potassium, and creatinine was calculated.

For logistic reasons the rural based controls were studied as a cohort over the two years coinciding with the middle two years of the four year recruitment and follow up period of the migrants (August 1981 to August 1985). We used a recent census to match controls for age, sex, and village of residence (estimated from the data on migrants recruited during the first six months of the study). The same investigations were made on controls as on the migrants, except that the controls were studied in one of five local clinics (converted school classrooms) and fewer diet histories were recorded for each individual as the diet was more uniform in the rural area.

The data were coded and analysed with the statistical package for the social sciences. The distributions of variables by sex and place of residence were calculated; adjustments for age and other covariates were made by analysis of variance and regression techniques, as appropriate.

\section{Results}

Over $95 \%$ of the people who moved to Nairobi and were eligible for the study were located and studied at least once during their stay. Once located, fewer than
$2 \%$ of the migrants refused to take part in the study. The initial investigations (at 0 month) took place, on average, one month after arrival in Nairobi.

Table I shows the age distribution of controls and migrants at the first examination. Because the numbers of subjects aged $<15$ and $\geqslant 35$ years were small and unevenly distributed between the urban and rural groups, all subsequent analyses were restricted to people aged 15-34. The numbers of such subjects who were available at each visit are indicated in figure 1 .

TABLE I-Age at first visit, sex and numbers of subjects participating in study of blood pressure and migration

\begin{tabular}{cccccc}
\hline & \multicolumn{2}{c}{ Men } & & \multicolumn{2}{c}{ Women } \\
\cline { 2 - 3 } \cline { 5 - 6 } (years $)$ & Rural group & Urban group & & Rural group & Urban group \\
\hline$<15$ & 3 & 1 & & 1 & 0 \\
$15-19$ & 119 & 68 & & 16 & 52 \\
$20-24$ & 26 & 72 & & 34 & 64 \\
$25-29$ & 14 & 18 & & 33 & 27 \\
$30-34$ & 15 & 5 & & 10 & 8 \\
$35-39$ & 7 & 3 & & 6 & 0 \\
$40-44$ & 3 & 1 & & 7 & 1 \\
$45-49$ & 2 & 3 & & 7 & 0 \\
$\geqslant 50$ & 6 & 1 & & 3 & 1 \\
\hline Total & 195 & 172 & & 117 & 153 \\
\hline
\end{tabular}

Table II shows the sex specific, age adjusted mean values of variables in controls and migrants at the first and subsequent follow up visits. Significance tests should be interpreted cautiously because of the large number of variables tested and the decreasing number of subjects with each follow up visit. In both men
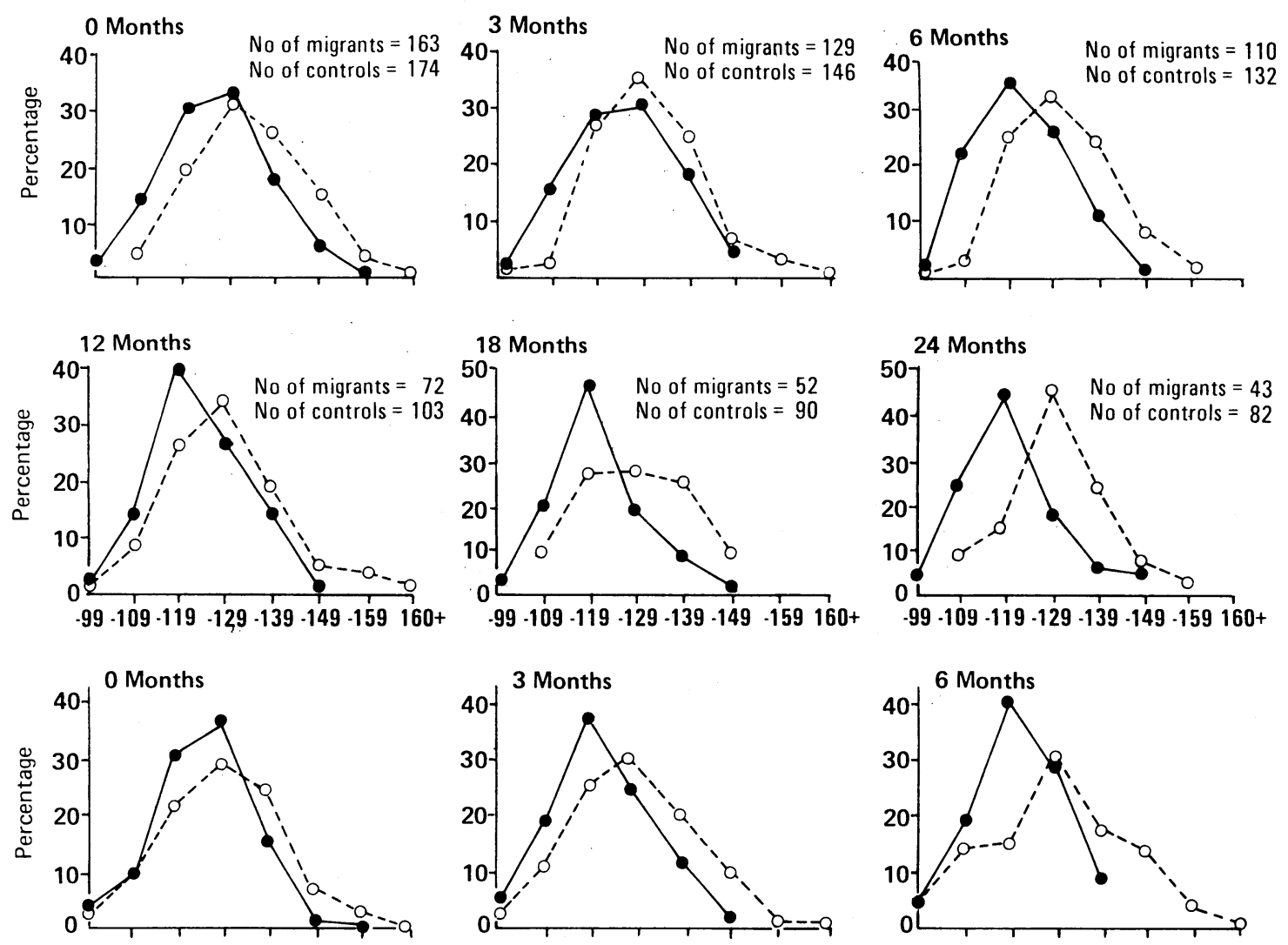

FIG $1-$ Frequency distribution of systolic (top) and diastolic (bottom) blood pressure ( $\mathrm{mm} \mathrm{Hg}$ ) among male migrants and controls. Controls, - - Migrants
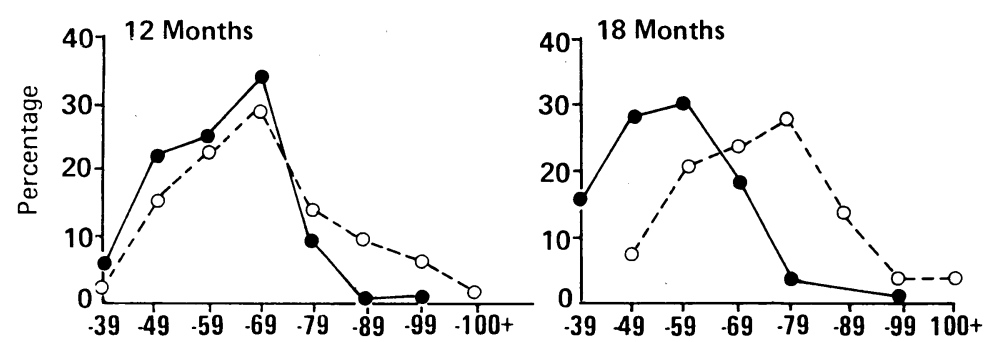

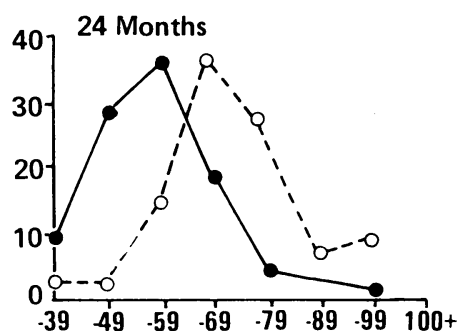


and women mean systolic blood pressure differed significantly between urban and rural groups at the first visit. Although mean systolic blood pressures fell in both groups with subsequent visits, the differences in systolic pressure between rural and urban groups were consistently maintained over 24 months of follow up. The mean diastolic blood pressure among men also differed significantly between the two groups at the first visit. Values fell over time in controls but increased in migrants so that the difference in pressure was larger at 24 months of follow up. No significant difference was found in diastolic pressure between women in the two groups at the first visit but the trends in blood pressure with time were similar to those seen

TABLE II-Mean (SD) of variables measured in subjects aged 15-34 years at various intervals after initial contact

\begin{tabular}{|c|c|c|c|c|c|c|}
\hline \multirow{2}{*}{$\begin{array}{l}\text { Time after } \\
\text { initial contact } \\
\text { (months) }\end{array}$} & \multicolumn{3}{|c|}{ Men } & \multicolumn{3}{|c|}{ Women } \\
\hline & Rural group & Urban group & $\mathrm{p}$ Value & Rural group & Urban group & p Value \\
\hline \multicolumn{7}{|c|}{ Systolic blood pressure $(\mathrm{mm} \mathrm{Hg})$} \\
\hline 0 & $120 \cdot 6(11 \cdot 6)$ & $129 \cdot 1(12.7)$ & $<0 \cdot 001$ & $112.39 \cdot 7$ & $119 \cdot 0(11 \cdot 2)$ & $<0.001$ \\
\hline 3 & $119 \cdot 9(11 \cdot 3)$ & $125.6(11.5)$ & $<0.001$ & $111.7 \quad 8.7)$ & $115 \cdot 5(10 \cdot 9)$ & 0.008 \\
\hline 6 & $117.4(10.7)$ & $125.9(11.7)$ & $<0.001$ & $107 \cdot 7 \quad 9 \cdot 6)$ & $115 \cdot 3(12 \cdot 9$ & $<0.001$ \\
\hline 12 & $118.6(10.8)$ & $123 \cdot 2(13 \cdot 2)$ & 0.01 & $107.5(9 \cdot 3)$ & $113.9(10.9)$ & 0.001 \\
\hline 18 & $115 \cdot 7(10 \cdot 1)$ & $125 \cdot 6(15 \cdot 5)$ & $<0.001$ & $108.1(9 \cdot 7)$ & $113 \cdot 2(9 \cdot 0)$ & 0.02 \\
\hline 24 & $117 \cdot 0(11 \cdot 4)$ & $125 \cdot 6(10.9)$ & $<0.001$ & $106 \cdot 2(9 \cdot 2)$ & $113 \cdot 7(9 \cdot 9)$ & 0.005 \\
\hline \multicolumn{7}{|c|}{ Diastolic blood pressure $(\mathrm{mm} \mathrm{Hg})$} \\
\hline 0 & $60.4(10.8)$ & $64 \cdot 3(14 \cdot 5)$ & 0.007 & $60 \cdot 5(9 \cdot 6)$ & $59 \cdot 4(11 \cdot 3)$ & 0.47 \\
\hline 3 & $57.6(12 \cdot 0)$ & $64 \cdot 0(13 \cdot 9)$ & $<0.001$ & $56.7(8 \cdot 8)$ & $58 \cdot 0(13 \cdot 8)$ & $\begin{array}{l}0.41 \\
0.44\end{array}$ \\
\hline 6 & $56 \cdot 5(10 \cdot 1)$ & $65.0(16.0)$ & $<0.001$ & $56 \cdot 3(10 \cdot 2)$ & $60.3(12.9)$ & 0.03 \\
\hline 12 & $56 \cdot 9(12 \cdot 1)$ & $63 \cdot 5(15 \cdot 6)$ & 0.002 & $57.2(10.8)$ & $58.9(10.0)$ & 0.42 \\
\hline 18 & $51 \cdot 2(11 \cdot 4)$ & $67 \cdot 6(15 \cdot 2)$ & $<0.001$ & $55 \cdot 1(10.1)$ & $61.5(11.5)$ & 0.009 \\
\hline 24 & $53 \cdot 1(12 \cdot 2)$ & $66 \cdot 3(14 \cdot 0)$ & $<0.001$ & $54.9(9.6)$ & $61.7(9 \cdot 3)$ & 0.008 \\
\hline \multicolumn{7}{|c|}{ Weight $(\mathrm{kg})$} \\
\hline 0 & $56 \cdot 6(8 \cdot 1)$ & $59 \cdot 2(7 \cdot 4)$ & 0.002 & $55.6(8.0)$ & $58 \cdot 1 \quad(7 \cdot 9)$ & 0.02 \\
\hline 3 & $56.9(7.9)$ & $59 \cdot 3(7 \cdot 2)$ & 0.005 & $55.8 \quad(8.2)$ & $58.8 \quad 8.0$ & 0.01 \\
\hline 6 & $58 \cdot 8 \quad(7 \cdot 8)$ & $60 \cdot 0(7 \cdot 7)$ & 0.80 & $57.8 \quad(8.5)$ & $58 \cdot 2(7 \cdot 4)$ & 0.69 \\
\hline 12 & $59 \cdot 2(7 \cdot 4)$ & $59 \cdot 3(7 \cdot 7)$ & 0.93 & $57.5 \quad 8.8)$ & $58.0 \quad 6.0)$ & 0.73 \\
\hline 18 & $57.8 \quad(6.8)$ & $60 \cdot 1(7 \cdot 1)$ & 0.06 & $54.8(7.0)$ & $57.4 \quad 6.3)$ & 0.11 \\
\hline 24 & $59 \cdot 2(6 \cdot 6)$ & $60 \cdot 0 \quad 6 \cdot 4$ & 0.55 & $55.5(7.6)$ & $58.6(8.0)$ & $0 \cdot 11$ \\
\hline \multicolumn{7}{|c|}{ Pulse rate (beats per minute) } \\
\hline 0 & $67 \quad(10)$ & $71 \quad(12)$ & 0.001 & 71 & & 0.003 \\
\hline 3 & 64 (10) & 69 (11) & 0.001 & $72 \quad(10)$ & $74 \quad 9)$ & 0.33 \\
\hline 6 & & & 0.004 & & & 0.08 \\
\hline 12 & $66 \quad(10)$ & $69 \quad(12)$ & $0 \cdot 10$ & $69 \quad(12)$ & $75 \quad(10)$ & 0.01 \\
\hline 18 & 63 (10) & $68 \quad$ (11) & 0.003 & $69 \quad 8$ & 70 & 0.64 \\
\hline 24 & $65 \quad$ (11) & $65 \quad(10)$ & 0.78 & 67 & 70 & $0 \cdot 14$ \\
\hline
\end{tabular}

TABLE III-Details of analysis of three 12 hour overnight urine samples for each subject aged 15-34 at various times after initial contact. All values given as mean $(S D)$ for each group

\begin{tabular}{|c|c|c|c|c|c|c|}
\hline \multirow{2}{*}{$\begin{array}{c}\text { Time after } \\
\text { initial contact } \\
\text { (months) }\end{array}$} & \multicolumn{3}{|c|}{ Men } & \multicolumn{3}{|c|}{ Women } \\
\hline & Rural group & Urban group & $\mathrm{p}$ Value & Rural group & Urban group & $\mathrm{p}$ Value \\
\hline \multicolumn{7}{|c|}{ Mean total urinary $\mathrm{Na}: \mathrm{K}$ ratio } \\
\hline 0 & $2 \cdot 5(1 \cdot 2)$ & $4 \cdot 3(1 \cdot 7)$ & $<0.001$ & $2 \cdot 8(1 \cdot 3)$ & $4.0(1.9)$ & $<0.001$ \\
\hline 3 & $2 \cdot 3(1 \cdot 2)$ & $4 \cdot 6(1.9)$ & $<0.001$ & $2 \cdot 8(1 \cdot 3)$ & $3.9(1.7)$ & $<0.001$ \\
\hline 6 & $2 \cdot 3(1 \cdot 0)$ & $4 \cdot 8(2 \cdot 2)$ & $<0.001$ & $2 \cdot 5(1 \cdot 2)$ & $3.8(1.4)$ & $<0.001$ \\
\hline 12 & $2 \cdot 3(1.0)$ & $4 \cdot 5(2 \cdot 2)$ & $<0.001$ & $2 \cdot 6(1 \cdot 3)$ & $3.9(1.6)$ & $<0.001$ \\
\hline 18 & $2 \cdot 5(1.3)$ & $4 \cdot 5(2 \cdot 2)$ & $<0.001$ & $2.5(1.2)$ & $3.8(1.6)$ & $<0.001$ \\
\hline 24 & $2 \cdot 8(1 \cdot 6)$ & $4 \cdot 3(2 \cdot 0)$ & $<0.001$ & $2 \cdot 7(1 \cdot 1)$ & $3 \cdot 9(1 \cdot 5)$ & $<0.001$ \\
\hline \multicolumn{7}{|c|}{ Mean total urine sodium (mmol/l) } \\
\hline 0 & $36(16)$ & $49(22)$ & $<0.001$ & $39(19)$ & $53(24)$ & $<0.001$ \\
\hline 3 & $33(17)$ & $50(18)$ & $<0.001$ & $35(15)$ & $55(22)$ & $<0.001$ \\
\hline 6 & $32(16)$ & $50(24)$ & $<0.001$ & $37(23)$ & $51(21)$ & $<0.001$ \\
\hline 12 & $32(17)$ & $44(18)$ & $<0.001$ & $35(16)$ & $49(20)$ & 0.001 \\
\hline 18 & $36(18)$ & $55(20)$ & $<0.001$ & $32(23)$ & $46(17)$ & $0 \cdot 10$ \\
\hline 24 & $31(16)$ & $52(22)$ & $<0.001$ & $35(24)$ & $49(18)$ & $0 \cdot 11$ \\
\hline \multicolumn{7}{|c|}{ Mean total potassium $(\mathrm{mmol} / \mathrm{l})$} \\
\hline 0 & $18(9)$ & $13(7)$ & $<0.001$ & $18(8)$ & 156 & $<0.01$ \\
\hline 3 & $17(8)$ & $14(7)$ & 0.003 & $20(8)$ & 146 & 0.06 \\
\hline 6 & $17(10)$ & $12(7)$ & $<0.001$ & $18 \quad(9)$ & $15(7)$ & $<0.03$ \\
\hline 12 & $16(8)$ & $12(7)$ & 0.002 & $18(10)$ & $14(7)$ & $0 \cdot 11$ \\
\hline 18 & 18 (11) & $13(5)$ & 0.05 & $22(13)$ & $17(10)$ & 0.35 \\
\hline 24 & $14(10)$ & $14(6)$ & 0.91 & $16(7)$ & $15(7)$ & 0.66 \\
\hline \multicolumn{7}{|c|}{ Mean total creatinine (mmolll) } \\
\hline 0 & $4 \cdot 8(1 \cdot 7)$ & $5 \cdot 0(1 \cdot 9)$ & 0.23 & $4 \cdot 2(1 \cdot 4)$ & $4 \cdot 1(1 \cdot 3)$ & $0 \cdot 60$ \\
\hline 3 & $3.9(1.7)$ & $4 \cdot 1(1 \cdot 2)$ & 0.40 & $3.4(1.0)$ & $3.4(0.7)$ & 0.87 \\
\hline 6 & $4 \cdot 6(1 \cdot 6)$ & $4 \cdot 7(1.7)$ & 0.58 & $3.9(1.6)$ & $4 \cdot 2(1 \cdot 2)$ & $0 \cdot 24$ \\
\hline 12 & $4.7(1.7)$ & $5 \cdot 0(2 \cdot 2)$ & 0.35 & $3.8(1.0)$ & $4 \cdot 0(1 \cdot 2)$ & 0.27 \\
\hline 18 & $3.9(1.3)$ & $4 \cdot 3(1 \cdot 2)$ & $0 \cdot 14$ & $3.6(1.0)$ & $3 \cdot 6(1 \cdot 1)$ & 0.97 \\
\hline 24 & $4 \cdot 3(1 \cdot 6)$ & $5 \cdot 5(2 \cdot 0)$ & 0.01 & $3.6(1 \cdot 1)$ & $3 \cdot 8(1 \cdot 5)$ & 0.75 \\
\hline
\end{tabular}

TABLE IV-Regression of blood pressure ( $\mathrm{mm} \mathrm{Hg}$ ) with age (year) in rural controls and urban migrants aged 15-34 years

\begin{tabular}{|c|c|c|c|}
\hline & & \multicolumn{2}{|c|}{ Slope $(\mathrm{SE})$} \\
\hline & & Rural & Urban \\
\hline \multicolumn{4}{|l|}{ Men: } \\
\hline 0 month & $\left\{\begin{array}{l}\text { Systolic } \\
\text { I Diastolic }\end{array}\right.$ & $\begin{array}{l}0.15(0.26) \\
0.47(0.25)\end{array}$ & $\begin{array}{l}0.19(0.49) \\
1.48(0.67)^{\star}\end{array}$ \\
\hline 6 months \{ & $\left\{\begin{array}{l}\text { Systolic } \\
\text { Diastolic }\end{array}\right.$ & $\begin{array}{l}0.22(0.23) \\
0.57(0.21)^{\star}\end{array}$ & $\begin{array}{l}0.340 .53) \\
1.97(0.72+\end{array}$ \\
\hline 24 months \{ & $\left\{\begin{array}{l}\text { Systolic } \\
\text { Diastolic }\end{array}\right.$ & $\begin{array}{r}-0.02(0.26) \\
0.52(0.26)^{\star}\end{array}$ & $\begin{array}{l}0.95(0.44) \star \\
1.89(0.51) \dagger\end{array}$ \\
\hline $\begin{array}{l}\text { Women: } \\
0 \text { month }\end{array}$ & $\left\{\begin{array}{l}\text { Systolic } \\
\text { Diastolic }\end{array}\right.$ & $\begin{array}{r}-0.06(0.30) \\
0.34(0.27)\end{array}$ & $\begin{array}{r}-1.71(0.75)^{\star} \\
0.25(0.79)\end{array}$ \\
\hline 6 months \{ & $\left\{\begin{array}{l}\text { Systolic } \\
\text { Diastolic }\end{array}\right.$ & $\begin{array}{l}0.13(0.31) \\
0.43(0.27)\end{array}$ & $\begin{array}{r}-0.17(0.82) \\
0.49(0.58)\end{array}$ \\
\hline 24 months \{ & $\left\{\begin{array}{l}\text { Systolic } \\
\text { Diastolic }\end{array}\right.$ & $\begin{array}{l}0.05(0.29) \\
0.82(0.28) \dagger\end{array}$ & $\begin{array}{r}-0.65(0.63) \\
0.62(0.59)\end{array}$ \\
\hline
\end{tabular}

${ }^{\star} \mathrm{p}<0.05$.

tp $<0.01$ (significance of slopes)

$\ddagger \mathrm{p}<0 \cdot 01$ (urban $v$ rural slopes).

in men and diastolic pressure differed significantly at six and 12 months.

The male migrants were significantly heavier than the controls at the first visit but the mean weight of the controls increased such that at six months and thereafter the two groups did not differ significantly. The significant differences in mean weights between control and migrant women at 0 and three months disappeared at six and 12 months but the difference, although not significant, was restored by 18 months.

Pulse rates were significantly higher in urban compared with rural groups in both sexes at the first visit. The mean rates decreased over 24 months in all groups and differences between the two groups became less apparent.

Table III gives details of the analysis of 12 hour overnight urine samples. The mean ratio of urinary sodium to potassium concentrations differed significantly between urban and rural groups in both sexes throughout the study. In both men and women these differences were due to consistently higher urinary sodium and lower urinary potassium concentrations among the urban group. Although the size of the difference was constant, it was not always significant because of the decreased number of subjects at each follow up. Creatinine excretion tended to be higher in urban than in rural subjects but differences were significant only at the 24 month visit in men.

Figures 1 and 2 show the distribution of systolic and diastolic blood pressure in migrants and controls at each of the six visits. In both men and women the distribution of systolic pressure was shifted slightly to the right at the first visit; this shift increased over 24 months. Although appearing more congruent initially, the diastolic pressures of urban and rural men and women were also clearly separated at 24 months.

The distribution of the migrants' blood pressure shifted to the right. This was further illustrated by analysing the percentage of the urban and rural groups who had blood pressures above and below arbitrary cut off values. In general, differences between the two groups were greater for men than for women, and for systolic rather than diastolic pressure. Overall, the percentage of the population above the arbitrary value of $140 \mathrm{~mm} \mathrm{Hg}$ systolic pressure and 80 or $90 \mathrm{~mm} \mathrm{Hg}$ for diastolic pressure was greater in the urban group at all visits. In addition, the percentage of the population with blood pressure below an arbitrary value of $110 \mathrm{~mm} \mathrm{Hg}$ (systolic) or $50 \mathrm{~mm} \mathrm{Hg}$ (diastolic) was greater in the rural group.

Table IV shows the regression of blood pressure with age in controls and migrants at the first ( 0 month) visit, six months, and 24 months. Systolic pressure rose significantly with age among men in the rural 

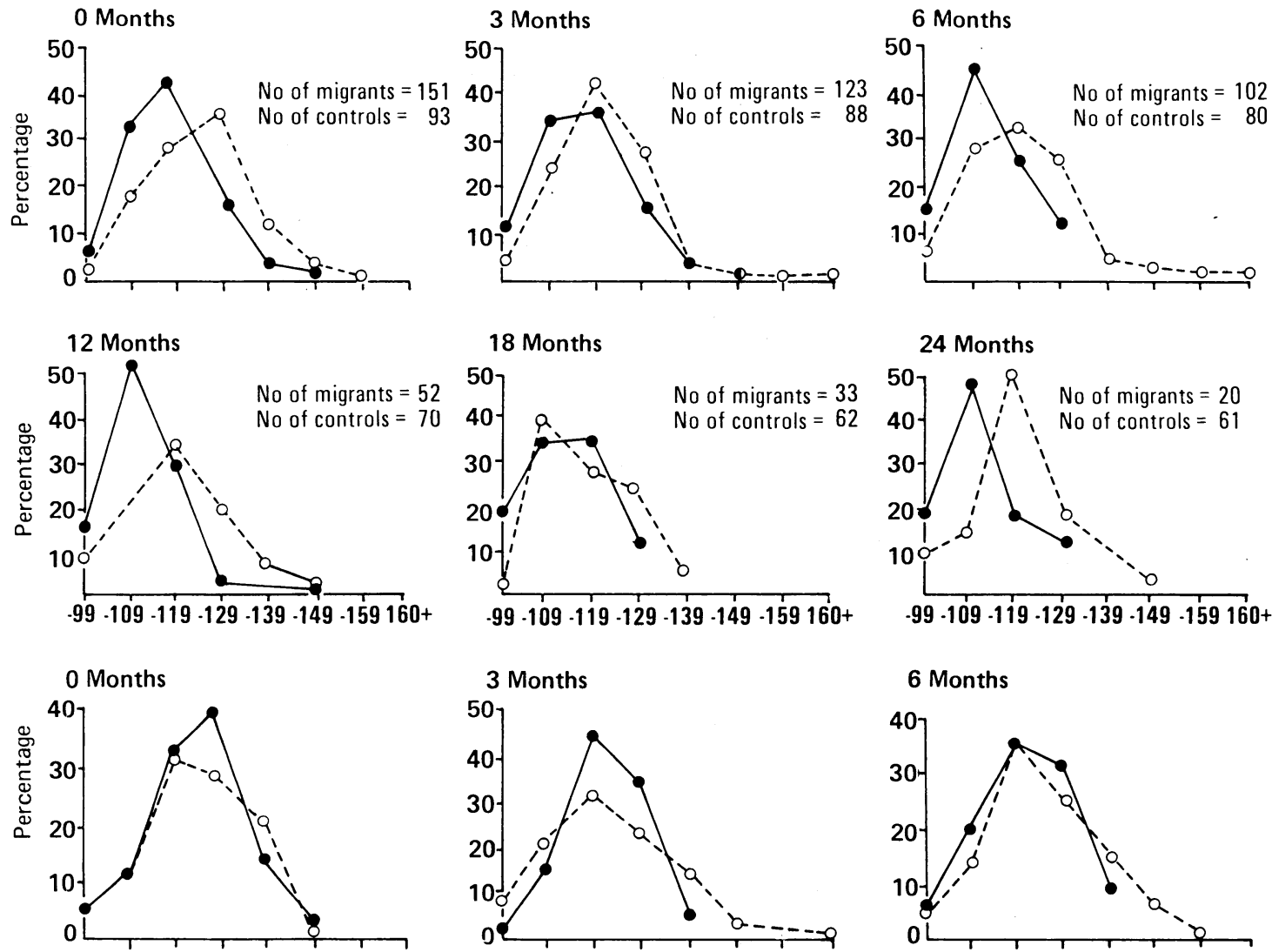

FIG 2-Frequency distribution of systolic (top) and diastolic (bottom) blood pressure $(\mathrm{mm} \mathrm{Hg})$ among female migrants and controls. Controls, -- Migrants
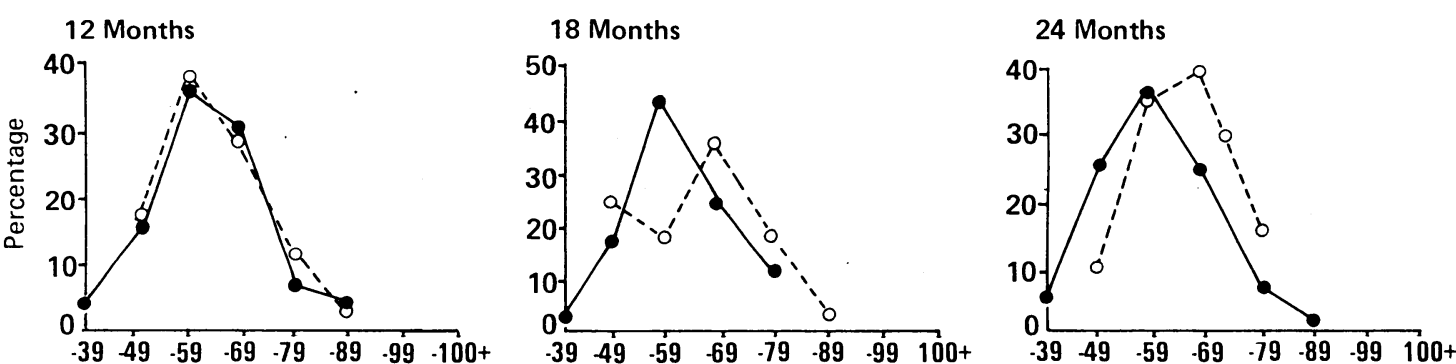

group. In contrast, though systolic blood pressure of men in the urban group showed no significant rise with age at the first visit, the slope of systolic blood pressure with age increased with time at six months and was significant by 24 months. By 24 months, the slopes of systolic blood pressure with age differed significantly between men in the urban and rural groups. The slope of diastolic blood pressure with age was greater in urban than in rural men from the first visit; these differences remained through the 24 months of follow. up. There were no significant differences in the slope of blood pressure with age between urban and rural women, nor were any consistent trends apparent over time in women.

Fewer women smoked or drank alcohol than men and the percentage of men who drank any alcohol or more than 28 units per week was generally higher, though not significantly so, in the rural group.

\section{Discussion}

The demographic trends of Luo migrants provide a unique opportunity to observe a natural experiment to investigate the causes of changes in blood pressure associated with migration. Though numerous cross sectional studies have documented differences in blood pressure of urban and rural populations, we believe this to be the first longitudinal study of blood pressure in which migrants have been followed up over time.

The main new finding was that differences in blood pressure between rural and urban groups were apparent by, on average, one month after urban migration. We also found that the new environment affected the whole population distribution of blood pressure, which was shifted to the right. Distinct subgroups with varying susceptibility to the critical environmental agents were not apparent; not only was the percentage of people with hypertension greater among migrants but the percentage of those with low blood pressure was also less in the migrants than in the controls.

Because this was an observational longitudinal study, there are potential problems in interpreting the results. Firstly, as the subjects were not randomly allocated to migrate it is possible that the differences in blood pressure were due to selective migration of individuals who had higher blood pressures, particularly as differences were apparent by the first month of migration. Other data, however, suggest that this is not the explanation. ${ }^{12}$ For example, of the 163 new male migrants, 90 had been examined before migration (mean 329 days). At their first visit after migration their blood pressure was consistent with that of other migrants, but their mean blood pressure in the rural area $(120 \cdot 9 / 59 \cdot 0 \mathrm{~mm} \mathrm{Hg})$ was identical with that of the rural controls $(120 \cdot 5 / 60 \cdot 5 \mathrm{~mm} \mathrm{Hg})$. In addition, the time elapsing after migration before the blood pressure was measured correlated significantly with the migrants' blood pressures. ${ }^{12}$ These observations were thus consistent with the notion that the initial increase 
in migrants' blood pressures occurred very soon after their arrival in the urban area.

A small part $(2-3 \mathrm{~mm} \mathrm{Hg})$ of the initial differences between the blood pressures of migrants and controls may be explained by the fact that migrants were studied in their new homes and controls in clinics. We have previously reported that in the rural population blood pressures recorded in the home are slightly higher than those recorded in clinics (2.9/ $2.3 \mathrm{~mm} \mathrm{Hg}$ ). ${ }^{13}$ The differences in blood pressure patterns after the initial visits, however, are much less likely to be affected by this possible bias.

Systolic and diastolic blood pressures showed differing patterns over time. The mean systolic blood pressure of all subjects was highest at the initial visit and fell thereafter; this is consistent with familiarisation with blood pressure measurement. ${ }^{14}$ The difference in distribution of blood pressure between urban and rural populations, however, became more distinct in both sexes over the 24 months of follow up. In contrast, mean diastolic pressure decreased over time in the rural group and tended to increase among migrants such that the distribution of diastolic pressures diverged appreciably over 24 months. The differing systolic and diastolic patterns suggest that separate mechanisms may be responsible for differences between the two groups or, more likely, that the relative contribution of two or more mechanisms influencing blood pressure may exert differential effects on systolic and diastolic pressure at different times during the study.

Most people migrated to Nairobi to search for work and if they failed in this they often returned to their rural home or moved to another town. Hence people moved away from both the rural and urban study areas and were lost to follow up. Such losses are unlikely to explain the differences in blood pressure patterns between urban and rural populations as results from analyses of the subset of individuals who had completed the whole 24 months of follow up were similar.

The prevalence of hypertension in a population is determined by the population distribution of blood pressure, and the fact that this can shift when the environment changes has profound implications for public health strategies. ${ }^{15}$ Identifying the determinants of this population shift is clearly critically important for public health.

Our results are consistent with several reports implicating high dietary sodium and low dietary potassium intake as determinants of the population distribution of blood pressure. ${ }^{16-18}$ The time scale of the blood pressure changes were, however, somewhat surprising, with significant blood pressure differences occurring within one month of urbanisation. Nevertheless, this agrees with recent findings in the highlands of Papua New Guinea, which showed increased blood pressure within 10 days of sodium supplementation in 10 subjects with a low sodium intake $(30 \mathrm{mmol} /$ day $) .{ }^{19}$

The significant differences in weight between migrants and controls at the first visit may have been due to one or more of several reasons. Regular quality control of weighing scales, however, makes errors in measurement unlikely, and previous data have shown that selective migration is not an appropriate explanation. ${ }^{12}$ The weight gain might reflect salt and water retention brought about by sodium loading associated with an urban diet. Rikimaru et al found that the acute effects of sodium loading include a transient increase in body weight thought to indicate accumulation of water. ${ }^{19}$ In addition, preliminary analysis of the semiquantitative diet histories showed that at 0 month the migrants did not ingest more energy than their rural counterparts, although this type of investigation might be insufficiently sensitive to detect the relatively small increase in energy intake necessary to produce the weight gain observed.

Clearly the blood pressure changes which accompany urbanisation could be due to numerous other factors including many in the diet (for example, calcium, magnesium, fibre), and analyses of several of these factors will be presented subsequently.

Migration is an extremely stressful life event, ${ }^{20}$ and pulse rate, a possible indicator of stress and anxiety, was higher among migrants. We have previously suggested that stress may potentiate the hypertensive effect of sodium loading, ${ }^{1121}$ which some animal" and clinical work ${ }^{23}$ has suggested may prevent the natriuresis normally associated with sodium loading. As the increase in blood pressure among migrants was larger than would be predicted from estimates based on electrolyte data from the Intersalt study ${ }^{2+}$ an additional mechanism may be implicated.

Though blood pressure differences between urban and rural groups were apparent at all visits, systolic blood pressures were highest in urban and rural men and women at the first visit, suggesting an acute stress effect with subsequent habituation to blood pressure measurement. This is supported by the observation that the pulse rates of migrants decreased with time. The data raise the possibility of an interaction between the effects of pulse rate (as surrogate for stress) and sodium intake on blood pressure. Such an interaction has been recently observed in two other populations. ${ }^{21}$

The interrelations among pulse rate, sodium intake, and blood pressure appear to change with time after migration. It may be that those factors initially responsible for the rise in blood pressure may become less important with time. For example, structural changes in the vasculature, which are a characteristic feature of hypertension, ${ }^{26}{ }^{27}$ may contribute to the long term maintenance of higher pressure.

A recent large multinational study ${ }^{24}$ confirmed the previously reported important effect of alcohol on blood pressure.$^{28}$ In the present study alcohol did not explain blood pressure differences between migrants and controls. The percentage of both alcohol drinkers $(>1$ unit per week) and heavy drinkers $(>28$ units per week) was similar in rural and urban groups. Interestingly, none of the four low blood pressure populations included in the Intersalt study showed a significant association between alcohol consumption and blood pressure. ${ }^{29}$ This may in part reflect the relatively low intake of alcohol in these populations or unsuitability of a questionnaire to evaluate intakes in such populations.

We also found that age had a different effect on systolic and diastolic blood pressure. Although mean systolic blood pressure differed significantly between men in the rural and urban groups, the slope of systolic blood pressure with age in the urban group remained relatively flat until 24 months, when it rose significantly. This suggests that the rise in systolic blood pressure associated with age occurred not at the initial urbanisation but over 24 months. For diastolic blood pressure, however, migrants had a significantly higher increase of blood pressure with age than controls at the first visit, and this was maintained over 24 months. Women showed no consistent changes of blood pressure in relation to age over time or between groups.

Differences between women in the urban and rural groups were generally consistent with the results in men but smaller. Furthermore, weight, pulse rate, and the ratio of sodium to potassium excretion were less consistently associated with blood pressure. This may have been due to the smaller number of women in the study or to the high percentage of women who were pregnant or lactating during the study.

These results support the view that the ratio of dietary sodium to potassium (as assessed by urine measurements), body weight, and possibly stress 
(reflected by pulse rate) are important predictors of the shift in blood pressure distribution observed when a low blood pressure community becomes urbanised. We would suggest that these same factors may play a part in at least the early stages of development of "essential hypertension."

This project was supported by the Wellcome Trust. We thank Clare Poulter and Jan Lury for fieldwork.

\footnotetext{
Kannel WB. Some lessons in cardiovascular epidemiology from Framingham. Am 7 Cardiol 1976:37:269-82.

2 Working Group on Arteriosclerosis of the National Heart, Lung and Blood Institute. Report of the working group on arteriosclerosis of the National Heart, L ung and Blood Institute. Bethesda: United States Department of Health and Human Services, Public Health Service, National Institutes of Health 1981: Vol 1, NIH No 81-2034; Vol 2, NIH No 81-0235.

3 Kannel WB, Neaton JD, Wentworth D, et al. Overall and coronary hear disease mortality rates in relation to major risk factors in 325348 men screened for the multiple risk factor intervention trial. A $m$ Heart 1986;112:825-36

4 Sinnett PF, Whyte HM. Epidemiological studies in a total highland population - Tukisenta, New Guinea: cardiovascular disease and relevant clinical electrocardiographic, radiologic and biochemical findings. I Chronic Dis 1973:26:265-9.

Truswell AS, Kennelly MB, Hansen JDL, Lee RB. Blood pressures of !kung bushmen in northern Botswana. Am Heart $f$ 1972;84:5-12.

6 Shaper AG, Wright DH, Kyobe J. Blood pressure and body build in three nomadic tribes of northern Kenya. East Afr Med f 1969;46:273-81.
not

7 Shaper AG, Leonard PJ, Jones KW, Jones M. Environmental effects on the body build, blood pressure and blood chemistry of nomadic warriors serving in the army in Kenya. East Afr Med f 1969;46:282-9.

8 Sever P, Gordon D, Peart WS, Beighton P. Blood pressure and its correlates in urban and tribal Africa. Lancet 1980;ii:60-4.

9 Cruz-Coke R, Etcheverry R, Nagel R. Influence of migration on blood pressure of Easter Islanders. Lancet 1964;i:697-9.

10 Sever PS, Poulter $N$. An hypothesis for the pathogenesis of essential hrpertension based on a new model of migration-induced blood pressure elevation. In: Hofman A, Grobbee DE, Schalekamp MADH, eds. Early pathogenesis of primary hypertension. Amsterdam: Elsevier, 1987. in Health 1984:38:181-6.
}

12 Poulter NR, Khaw KT, Sever PS. Higher blexd pressures of urban migrants from an African low blood pressure population are not due to selective migration. Am f Hypertens 1988;1:143-5S

13 Poulter NR, Lury J1), Thompson A. Blood pressures higher in the home than in the clinic in rural Kenya. F Eprdemiol Community Health 1986;40:186-7. 4 Medical Research Council Working Party. MRC trial of treatment of mild hypertension. Br.Med f 1985;291:97-104.

15 Rose G. Strategy of prevention: lessons from cardiovascular disease. Br Med 7 $1981 ; 282: 1847-51$

16 Meneely GR, Battarbee HD. High sodium-low potassium environment and hypertension. Am f Cardiol 1976;38:768-84.

17 Langford HG. Dietary potassium and hypertension: epidemiologic data. Ann Intern Med 1983;98:770-2.

18 Khaw KT, Rose G. Population study of blood pressure and associated factors in St Lucia, West Indies. Int F Epidemiol 1982;11:372-7.

19 Rikimaru T, Fujita Y, Okuda T, et al. Responses of sodium balance, blood pressure and other variables to sodium loading in Papua New Guinea pressure and other variables to sodium loditis
highlanders. Am f Clin Nutr 1988;47:502-8.

20 Scotch NA, Geiger JH. Epidemiology of essential hypertension: psychologic and socio-cultural factors in etiology. $\mathcal{F}$ Chronic Dis 1963;16:1183-21

21 Poulter NR, Shipley MJ, Bulpitt CJ, Markowe HJ, Marmot MG. Pulse rate and 24 hour urinary sodium content interact to determine blood pressure levels of male London civil servants. F Hypertens 1988;6 (suppl 4):611-3S.

22 Koepke JP, DiBona GF. High sodium intake enhances renal nerve and anti-natriuretic responses to stress in spontaneously hypertensive rats. Hypertension 1985;7:357-63.

23 Light KC, Koepke JP, Obrist PA, Willis PW. Psychological stress induces sodium and fluid retention in men at high risk for hypertension. Science 1983:220:429-31.

24 Intersalt Cooperative Research Group. Intersalt: an international study of electrolyte excretion and blood pressure. Results for 24 hour urinary sodium and potassium excretion. Br Med f 1988;297:319-28.

25 Straessen J, Bulpitt CJ, Thijs L, et al. Sympathetic tone and relation between sodium intake and blood pressure in the general population. Br Med $\mathcal{J}$ sodium intake an
1989:299:1502-3.

26 Folkow B, Grimby G, Thelesius $O$. Adaptive structural changes of the vascular walls in hypertension and their relation to the control of peripheral resistance. Acta Physiol Scand 1958; 44:255-72.

27 Lever AF. Slow pressor mechanisms in hypertension: a role for hypertrophy of resistance vessels? I Hypertens 1986;4:515-24.

28 Klatsky AL, Friedman GD, Seigelaub AB, Gerard MJ. Alcohol consumption and blood pressure: Kaiser-Permanente multiphasic health examination data. N Engl f Med 1977;296:1194-200.

29 Carvalho JJM, Baruzzi RG, Howard PF, et al. Blood pressure in 4 isolated small-village populations in the Intersalt study. Hypertension 1989;14:238-

(Accepted 15 fanuarv 1990)
Vascular Laboratories, St James's Hospital, PO Box 580, Dublin 8

Mary-Paula Colgan, MD, director

St George's Hospital, London

John A Dormandy, FRCS, consultant surgeon

Department of

Mathematics, University of Keele, Staffordshire

Peter W Jones, PHD, senior lecturer

Birch Hill Hospital, Rochdale, Lancashire Ivor G Schraibman, FRCS, consultant surgeon

Trinity College, Dublin D Gregor Shanik, FRCS, professor of vascular surgery

West Middlesex University Hospital, Isleworth, Middlesex

Richard A L Young, FRCS, consultant surgeon

Correspondence and requests for reprints to: Dr Colgan.

\section{Oxpentifylline treatment of venous ulcers of the leg}

Mary-Paula Colgan, John A Dormandy, Peter W Jones, Ivor G Schraibman, D Gregor Shanik, Richard A L Young

\section{Abstract}

Objective-To determine the effect of oxpentifylline on the healing of venous ulcers of the leg.

Design-Double blind, randomised, prospective, placebo controlled, parallel group study.

Setting-Four outpatient clinics treating leg ulcers in England and the Republic of Ireland.

Patients -80 Consecutive patients with clinical evidence of venous ulceration of the leg in whom appreciable arterial disease was excluded by the ratio of ankle to brachial systolic pressure being $>0 \cdot 8$.

Interventions-All patients received either oxpentifylline $400 \mathrm{mg}$ three times a day by mouth or a matching placebo for six months (or until their reference ulcer healed if this occurred sooner) in addition to a locally standardised method of compression bandaging.

Main outcome measures-The primary end point was complete healing of the reference ulcer within six months. The secondary end point was the change in the area of the ulcer over the six month observation period.

Results-Complete healing of the reference ulcer occurred in 23 of the 38 patients treated with oxpentifylline and in 12 of the 42 patients treated with a placebo. Life table analysis showed that the proportion of ulcers healed at six months was $64 \%$ in the group treated with oxpentifylline compared with $34 \%$ in the group treated with a placebo (log rank test $\chi^{2}=4.78, \mathbf{p}=0.03$ ), which was significant (odds ratio $=1 \cdot 81,95 \%$ confidence interval $1 \cdot 20$ to $2 \cdot 71$ ).

Conclusion-Oxpentifylline used in conjunction with compression bandaging improves the healing of venous ulcers of the leg.

\section{Introduction}

Venous ulcers of the leg are a common cause of illness in the community. The condition has a prevalence of $1 \%$, which is similar to that of diabetes, and it recurs chronically.' Ulcers of the leg are expensive to treat as they require regular dressing, often by district nurses. The cost to the NHS has been estimated to be $£ 1200$ for each unhealed ulcer a year. ${ }^{2}$ At present there is no proved pharmacological treatment, but this is not surprising as the pathophysiology of venous ulceration of the leg is poorly understood.

Two hypotheses have been advanced to explain the occurrence of venous ulcers of the leg in the context of the postphlebitic syndrome. ${ }^{34}$ The first hypothesis relates to the formation of a pericapillary cuff of fibrin, which acts as a barrier to diffusion and leads to local ischaemia of the tissues. ${ }^{56}$ The second hypothesis concerns the phenomenon of white cell trapping, which aggravates the trophic skin changes that are typically seen in patients with venous hypertension. ${ }^{\text {? }}$ Oxpentifylline (Trentai, Hoechst) has been found to have fibrinolytic effects ${ }^{9}$ and to influence the behaviour of white cells. ${ }^{10}$ It therefore seemed reasonable to study 